\title{
Physical activity, ambulation, and comorbidities in people with diabetes and lower-limb amputation
}

\author{
Roger J. Paxton, PhD; ${ }^{1}$ Amanda M. Murray, DPT, PhD; ${ }^{1-2}$ Jennifer E. Stevens-Lapsley, PT, PhD; ${ }^{1-2}$ Kyle A. \\ Sherk, MS, CPO; ${ }^{3}$ Cory L. Christiansen, PT, PhD ${ }^{1-2^{*}}$ \\ ${ }^{1}$ Physical Therapy Program, Department of Physical Medicine and Rehabilitation, University of Colorado, Aurora, \\ CO; ${ }^{2}$ Geriatric Research Education and Clinical Center, Department of Veterans Affairs Eastern Colorado Healthcare \\ System, Denver, CO; ${ }^{3}$ Hanger Orthotics and Prosthetics, Denver, CO
}

\begin{abstract}
We characterized physical activity (PA) and its relation to physical function and number of comorbidities in people with diabetes and transtibial amputation (AMP), people with diabetes without AMP, and nondisabled adults without diabetes or AMP. Twenty-two individuals with type 2 diabetes mellitus (DM) and transtibial amputation (DM+AMP), 11 people with DM, and 13 nondisabled participants were recruited for this cross-sectional cohort study. Measures included PA volume and intensity, a Timed Up and Go test, a 2-min walk test, and number of comorbidities. The nondisabled group performed greater amounts of PA than the DM group, who performed greater amounts of PA than the DM+AMP group. PA was related to physical function in the DM group and in the DM+AMP group, whereas no such relationship existed in the nondisabled group. PA was not related to number of comorbidities in any group. These findings suggest the ability to walk may affect overall performance of PA. Alternately, PA may alleviate walking problems. This possibility is of interest because issues with walking may be modifiable by improved levels and intensity of PA. PA's lack of relation to number of comorbidities suggests that factors beyond multiple morbidities account for group differences in PA.
\end{abstract}

Key words: comorbidities, diabetes, functional performance, lower-limb amputation, nondisabled adults, physical activity intensity, physical activity level, steps per day, transtibial amputation, walking performance.

\section{INTRODUCTION}

Walking performance is strongly related to quality of life, which is diminished by lower-limb amputation (LLA) [1-2]. Physical activity (PA) is a key indicator of walking performance that may influence quality of life in patients with LLA [3-4]. Objective clinical measures of walking performance using the 6-min walk test (6MWT), 2-min walk test (2MWT), and Timed Up and Go (TUG) are correlated with PA [3-4]. These relationships provide a negative view of physical function for patients with LLA because PA is severely limited by LLA. Severe limitations in performance of PA are not only linked to LLA but also comorbidities commonly found in conjunction with dysvascular amputation. In particular, type 2 diabetes mellitus (DM) is present in most people (73\%) who

\footnotetext{
Abbreviations: $2 \mathrm{MWT}=2$-min walk test, $6 \mathrm{MWT}=6$ - $\mathrm{min}$ walk test, $\mathrm{AMP}=$ transtibial amputation, $\mathrm{DM}=$ type 2 diabetes mellitus, $\mathrm{HbA} 1 \mathrm{c}=$ glycated hemoglobin, LLA $=$ lower-limb amputation, $\mathrm{NA}=$ nondisabled adult, $\mathrm{PA}=$ physical activity, $\mathrm{SD}=$ standard deviation, $\mathrm{TUG}=$ Timed $\mathrm{Up}$ and Go.

*Address all correspondence to Cory L. Christiansen, PT, PhD; Physical Therapy Program, Mailstop C-244, 13121 East 17th Ave, Aurora, CO 80045; 303-724-9101; fax: 303724-9016. Email: cory.christiansen@ucdenver.edu http://dx.doi.org/10.1682/JRRD.2015.08.0161
} 
undergo dysvascular LLA [5]. DM is related to low levels of PA and may compound or synergistically interact with dysvascular amputation to diminish PA levels [610]. This interaction is important, as PA is critical for effective management of chronic disease. In patients with $\mathrm{DM}$, performance of regular PA is associated with lower glycated hemoglobin (HbA1c) measurements [11]. Similarly, in people with LLA, lower levels of self-reported PA restriction are correlated with poorer quality of life in physical, psychological, and social domains [12].

Previous studies focused on PA performance after LLA typically included multiple levels of amputation and/or causes of amputation [3-4,13]. Only one investigation specifically focused on PA performance in patients with transtibial dysvascular amputation [8]. These patients engaged in walking and dynamic activities for $3.8 \pm 2.4$ percent and $4.3 \pm 2.6$ percent (mean \pm standard deviation [SD]) of $24 \mathrm{~h}$ periods, respectively. These values stand in contrast to values collected from nondisabled individuals who engaged in walking and dynamic activities for $9.7 \pm 4.2$ percent and $11.4 \pm 5.4$ percent (mean \pm $\mathrm{SD})$ of $24 \mathrm{~h}$ periods, respectively [8]. No relationships were found between PA and functional independence or performance, nor were any relationships reported between PA and comorbidities [8]. These findings collected from a distinct participant population suggest that PA studies more specifically focused by level of amputation, cause of amputation, and specific comorbidities may be required to reveal clinically important relationships and differences.

The purpose of this study was to characterize PA in people with DM and transtibial amputation (AMP), people with DM but without AMP, and nondisabled adults (NAs) without DM or AMP. We also examined the relationship among PA, performance-based measures of physical function, and number of comorbidities. We hypothesized that people with DM and LLA would be less active than people with DM and without LLA, and that both of these groups would be less active than NAs. We also hypothesized that PA would be related to both physical function and comorbidities in all groups.

\section{METHODS}

\section{Study Design}

This investigation was a cross-sectional study comparing PA across three groups: people with DM, people with DM+AMP, and NAs. The relationship of PA to func- tional performance and comorbidities was also investigated within each group.

\section{Participants}

Eleven people with DM, 22 people with DM+AMP, and 13 NAs were recruited from clinics and the community. All participants were $50-85$ yr of age, and none displayed an unstable heart condition, uncontrolled extreme hypertension, acute systemic infection, or pregnancy. Participants with DM and NAs displayed household ambulation or better, and all of the DM group displayed clinically diagnosed DM. All of the DM+AMP group had clinically diagnosed DM, unilateral dysvascular AMP $<6$ mo prior to screening, household ambulation or better using a prosthesis, participation in physical rehabilitation at time of testing, and no ankle-level or more proximal amputation on the contralateral limb. For ambulation in the community, $10 \mathrm{DM}+\mathrm{AMP}$ participants reported using a cane, 7 reported using a walker or two crutches/canes, 2 reported using a wheelchair, and 3 reported using no assistive device. No participants with DM without AMP or NAs used an assistive device during ambulation. Two participants with DM+AMP had amputation of the big toe, and one had a metatarsal amputation on the contralateral limb. No participants with DM without AMP or NAs had amputations.

\section{Data Collection}

\section{Physical Activity}

Each participant was issued an accelerometry-based PA monitor (ActiGraph GT3X or wGT3X-BT, ActiGraph; Pensacola, Florida) collecting data at $30 \mathrm{~Hz}$. ActiGraphs were securely fastened to each participant around the waist at the midaxillary line using an elastic belt and worn for 10 consecutive days [14-15]. Offline analysis was performed using ActiLife software (ActiGraph). PA level was quantified as steps/d. Intensity of activity was classified using the Freedson criteria to include percentage of time spent in sedentary, light, moderate, vigorous, and very vigorous activity [16]. Patients were allowed to use assistive devices (e.g., cane, walker) during PA data collection.

\section{Physical Function}

Walking performance and mobility were assessed in a single session, at the participant's home or a clinical research space, using the $2 \mathrm{MWT}$ and TUG. These tests 
are reliable across time and tester and are valid indicators of functional performance and mobility for patients with AMP and NAs [17-20]. Similar to collection of PA data, patients were allowed to use assistive devices during collection of physical function data. The TUG was performed using a standard height $(46 \mathrm{~cm})$ chair and a stopwatch to measure the time required by participants to stand from a seated position, walk forward $3 \mathrm{~m}$, turn, walk back to the chair, and return to the seated position as quickly as possible while remaining safe [21]. The 2MWT courses varied among participants $(6-30 \mathrm{~m})$ because assessment sessions performed in participants' homes sometimes limited the walking course that could be used. Surfaces of the walking courses varied from firm (e.g., granite) to soft (e.g., carpet), with all courses being flat, nonslippery, well lit, and clear of obstacles. Total distance walked for 2 consecutive min was assessed using a stopwatch. Participants were instructed to "cover the greatest distance possible in 2 min while remaining safe." [22]

\section{Comorbidities}

Individual comorbidities were quantified using the Functional Comorbidity Index [23]. This instrument allows up to 18 discrete diagnoses to be noted. This numeric score has been shown to be negatively correlated with functional performance in other populations with lower-limb dysfunction [23].

\section{Statistical Analyses}

All variables are represented using means and SD for continuous variables and frequencies for categorical variables. One-way analysis of variance $(\alpha=0.05)$ was used to characterize differences between DM, DM+AMP, and NA groups for PA, intensity of PA, TUG, 2MWT, and comorbidities. Pearson $r$ correlation coefficients were used to assess the relationship between PA and parametric variables including functional performance and mobility. Spearman rho correlation coefficients were used to assess the relationship between PA and the nonparametric variable comorbidities. Results in figures are presented as $r$ or $\rho$ (95\% confidence interval). SPSS version 22 (IBM; Armonk, New York) was used for all statistical analyses.

\section{RESULTS}

\section{Participant Characteristics}

Participant characteristics are noted in the Table. Participants in all groups were of similar age and height. No significant difference in mass or body mass index existed between the DM+AMP group and the DM group. The DM+AMP group had significantly greater mass and body mass index when compared to the NA group, whereas differences between the DM and NA groups did not reach significance. HbA1c levels were similar between the DM and DM+AMP groups. Functional Comorbidity Index scores were significantly different between all three groups, with the DM+AMP group displaying the greatest scores, the NA group displaying the least scores, and the DM group displaying intermediate scores.

\section{Physical Activity and Physical Function}

PA performance is noted in the Table. PA level performed was different for all three groups. The NA group exhibited the greatest amount of PA, followed by the DM and DM+AMP groups. In terms of PA intensity, the $\mathrm{DM}+\mathrm{AMP}$ group spent a greater amount of time sedentary than the DM and NA groups. The NA group spent more time in vigorous activity than the DM+AMP group, and notably, when calculated to the one-hundredths decimal position, neither the DM nor DM+AMP group was found to perform any vigorous or very vigorous PA. No other differences existed between groups or at other levels of PA intensity.

The DM group performed the TUG significantly faster than the DM+AMP group. The NA group also performed the TUG more quickly than the DM+AMP group, whereas no difference existed between the NA and DM groups. The NA group walked farther in the 2MWT than both the DM and DM+AMP groups. The 2MWT distance was greater in the DM group than in the DM+AMP group.

\section{Correlations Between Physical Activity, Physical Function, and Comorbidities}

PA was inversely related to time required to perform the TUG for both the DM+AMP and DM groups, but not the NA group (Figure 1). Similarly, PA performance was directly related to distance walked during the 2MWT for both the DM+AMP and DM groups, but not the NA group (Figure 2). Functional Comorbidity Index score was not related to PA for any group (Figure 3). 
JRRD, Volume 53, Number 6, 2016

Table.

Participant characteristics and performance (mean \pm standard deviation unless otherwise noted).

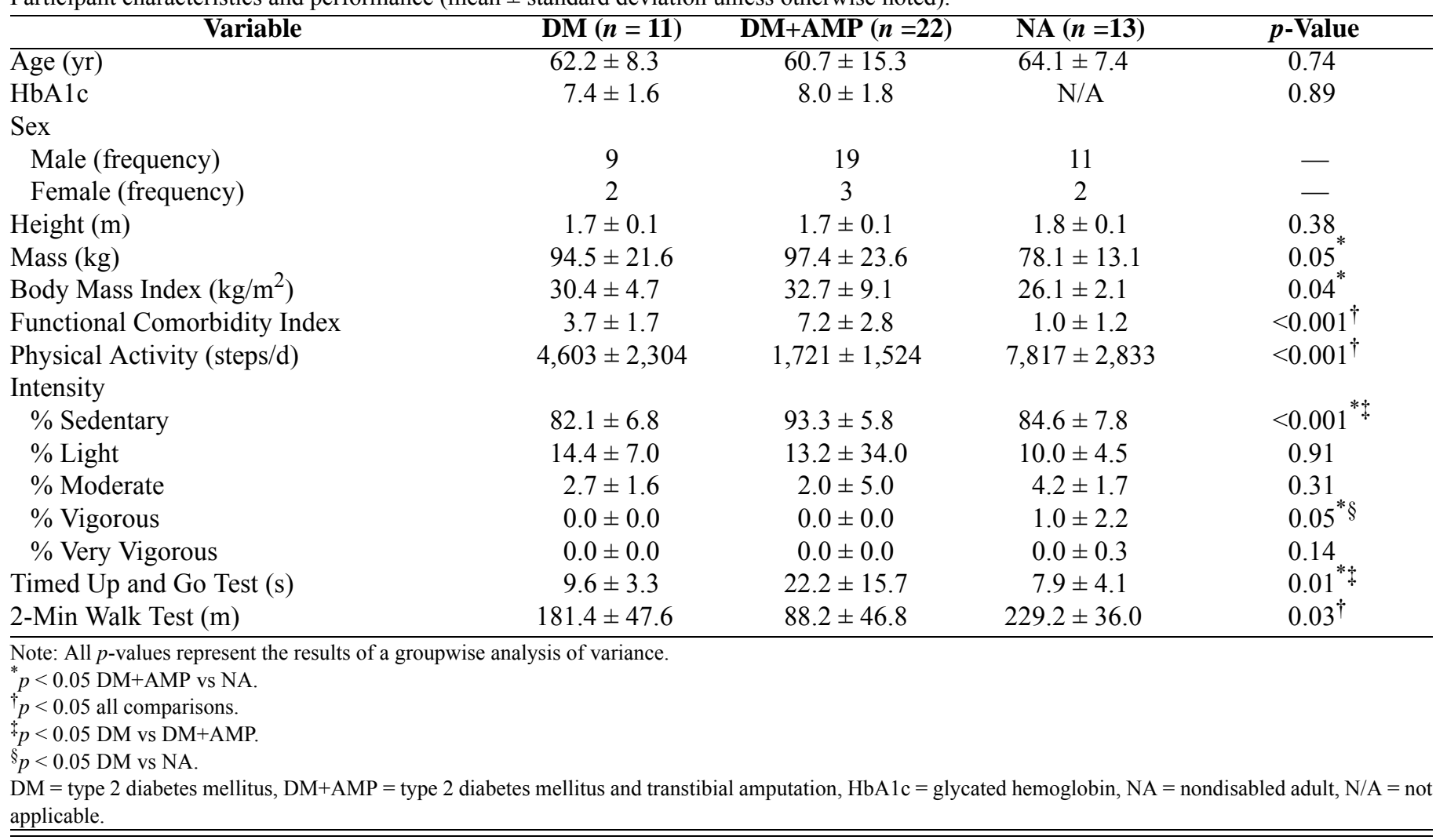

\section{DISCUSSION}

This study characterized PA in people with DM, people with DM and LLA, and NAs. Nondisabled individuals performed greater amounts of PA than the DM group who, in turn, performed greater amounts of PA than the DM+AMP group. We also examined the relationship among PA, clinical measures of physical function, and number of comorbidities. PA was related to physical function in the DM group as well as the DM+AMP group, but no such relationship existed in the NA group. PA was not related to number of comorbidities in any group.

Previous studies using accelerometry-based PA performance measures observed greater amounts of PA performed by people with LLA when compared with the $\mathrm{DM}+\mathrm{AMP}$ group $(1,721 \pm 1,524$ steps $/ \mathrm{d}$, mean $\pm \mathrm{SD})$ in the present study. Parker et al. found individuals with LLA at a variety of levels from various etiologies took $4,217 \pm 3,027$ steps/d (mean \pm SD) [4], and Lin et al. found a similar group of participants took 4,785 \pm
1,868 steps/d (mean \pm SD) [3]. Bussman et al. has been the only group to investigate PA specific to individuals with dysvascular AMP [8]. Involvement in dynamic PA was $4.3 \pm 2.4$ percent (mean $\pm \mathrm{SD}$ ) of each day and aligns more closely with our findings because the aforementioned studies included participants with amputation as a result of reasons other than dysvascular issues [8]. Individuals with dysvascular amputation are likely to have performed less PA historically, as evidenced by the activity levels of the DM group. The chronic low activity behavior prior to LLA may carry over to PA performed after amputation.

Several studies have compared PA of people with DM but without amputation with nondisabled controls using accelerometry. The low PA performed by people with DM in this study is consistent with previous findings. Steeves et al. found people with DM to be 33 percent less physically active than NAs, which aligns with the 41 percent difference found in the present study [9]. Similarly, Harris et al. found people with DM take 3,243 fewer steps/d than NAs [24]. This difference is virtually 
(a)

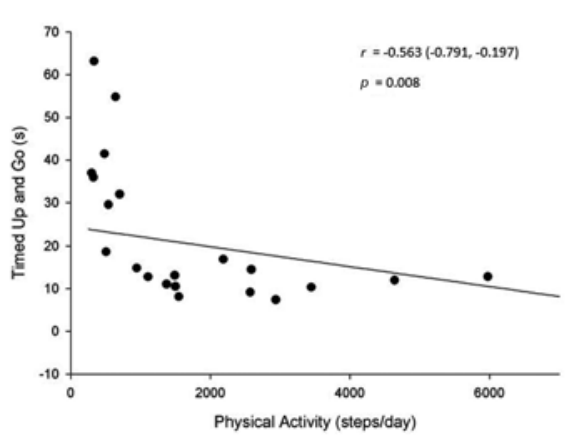

(b)

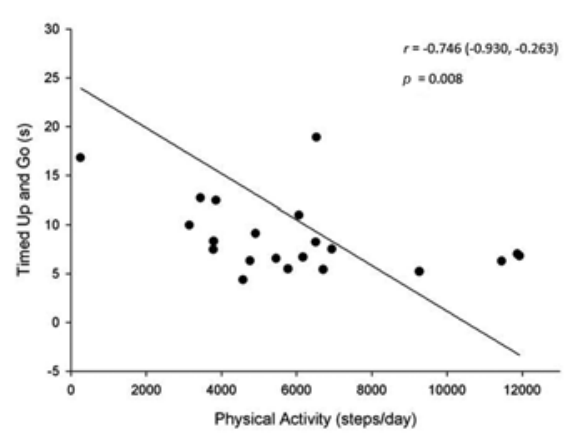

(c) Nondisabled

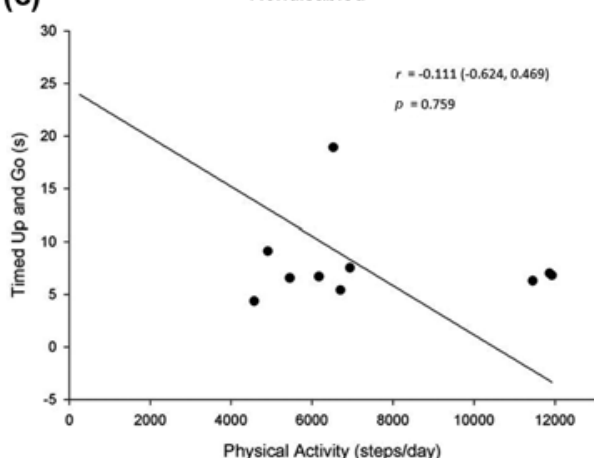

Figure 1.

Relationship between physical activity (steps/day) and Timed Up and Go test (s) performance for (a) DM+AMP, (b) DM, and (c) nondisabled groups. $\mathrm{DM}=$ type 2 diabetes mellitus, $\mathrm{DM}+\mathrm{AMP}=$ type 2 diabetes mellitus and transtibial amputation.

(a)

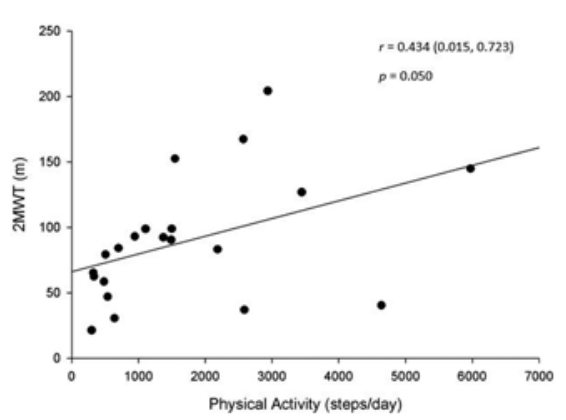

(b)

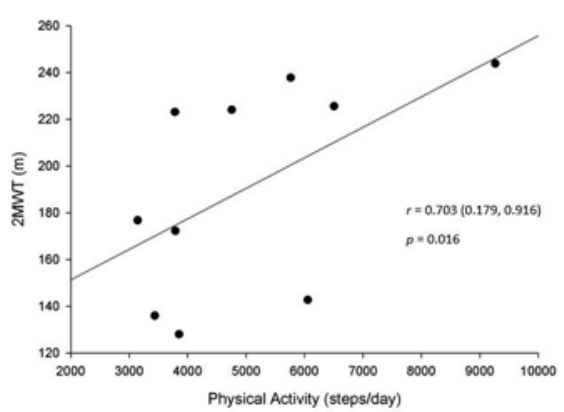

(c)

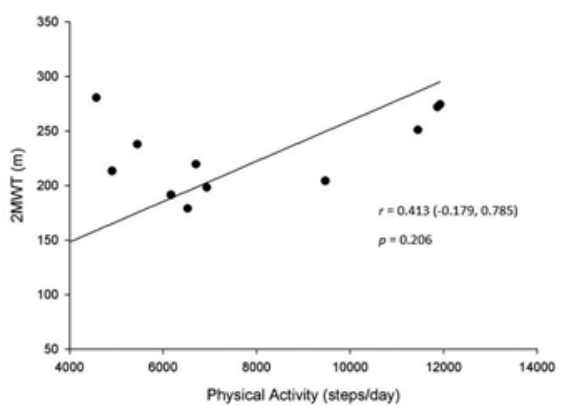

Figure 2.

Relationship between physical activity (steps/day) and 2MWT (m) performance for (a) DM+AMP, (b) DM, and (c) nondisabled groups. $2 \mathrm{MWT}=2$-min walk test, $\mathrm{DM}=$ type 2 diabetes mellitus, $\mathrm{DM}+\mathrm{AMP}=$ type 2 diabetes mellitus and transtibial amputation.

identical to the 3,214 steps/d variation found between the NA and DM groups in the present study. When comparing studies and/or groups within studies, the context of historic norms can be helpful. Tudor-Locke et al. noted individuals aged 60-64 yr take 4,761 to 6,127 steps daily [25]. Interestingly, this value aligns with the DM group in the present study, and the NA group would be classified in the highest tier of PA [25]. Although both of these groups appear to be more active than those described in previous studies, the DM group still performed less PA than the NA group. This difference is important because lesser amounts of PA can compound issues associated with DM and other comorbidities [26]. Of great relevance to this study is that insufficient amounts of PA in combination with DM are associated with peripheral artery disease, which can lead to dysvascular LLA [26-28].
The World Health Organization recommends that adults perform at least 150 min of moderate-intensity PA every week to maintain their health [29]. Interestingly, all three groups exceeded the recommended amount, with the DM+AMP group accruing $204 \mathrm{~min}$, the DM group accruing $275 \mathrm{~min}$, and the NA group accruing $423 \mathrm{~min}$ of moderate-intensity PA on average per week. For "additional health benefits," however, the World Health Organization recommends 300 min per week of moderateintensity PA [29]. Only the NA group achieved this level of PA, suggesting that both the DM and DM+AMP groups may need to perform additional PA to improve their physical health.

Previous studies indicate that individuals with amputation have low levels of PA. Although LLA serves as a barrier to PA, increasing PA may alleviate a variety of issues 
(a)

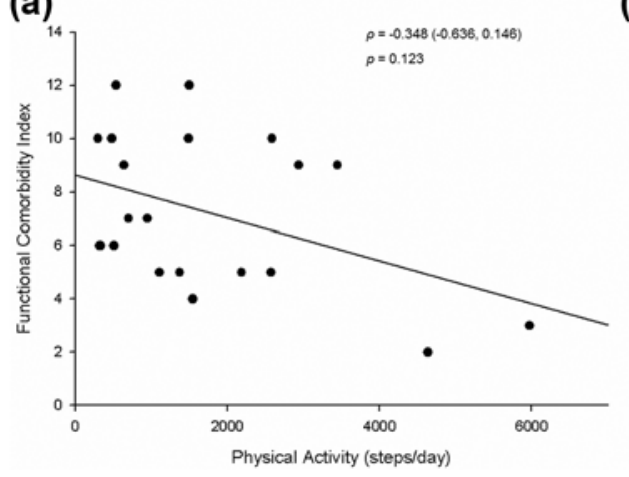

(b)

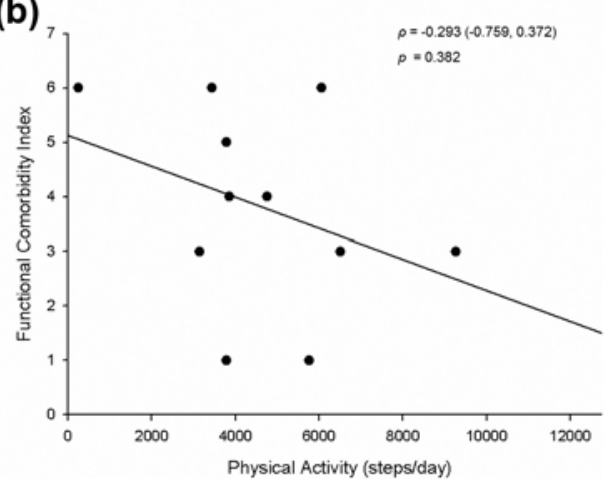

(c)

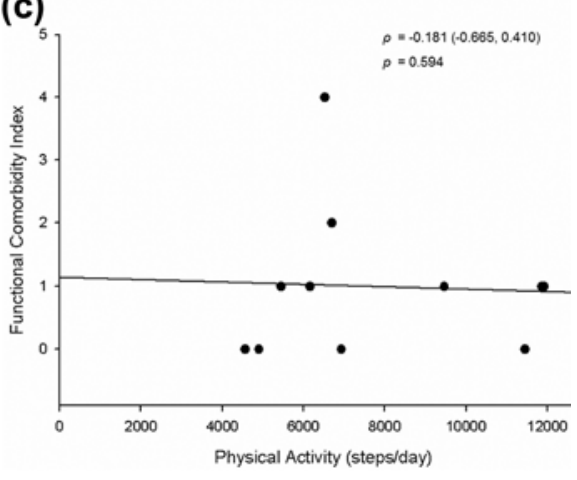

Figure 3.

Relationship between physical activity (steps/day) and Functional Comorbidity Index score for (a) DM+AMP, (b) DM, and (c) nondisabled groups. $\mathrm{DM}=$ type 2 diabetes mellitus, $\mathrm{DM}+\mathrm{AMP}=$ type 2 diabetes mellitus and transtibial amputation.

associated with amputation. For example, nontraumatic limb amputation is associated with a 54 percent mortality rate within 1 yr of amputation [30]. A review of 44 publications investigating the relationship of PA to mortality indicates that increased energy expenditure of $1,000 \mathrm{kcal}$ per week results in 20 percent to 30 percent reduced allcause mortality risk [31]. PA also reduces morbidity risk. Moderately and highly active individuals, for example, have 27 percent less chance of stroke than low-active individuals [32]. Low levels of PA for individuals with LLA present great risk in terms of future health complications and death.

Data regarding walking performance as assessed by the 2MWT is limited in people with DM and to an even greater extent in people with DM+AMP. The 2MWT performance demonstrated by the DM+AMP group is similar to values reported in similar populations [19,33]. Brooks et al. reported average distances of approximately $50 \mathrm{~m}$ and $140 \mathrm{~m}$ for inpatient and outpatient settings, respectively [18]. Gremeaux et al. reported an average distance covered of approximately $100 \mathrm{~m}$ [33]. This value is low compared with normative values of $150 \mathrm{~m}$ in older adults and aligns with the lower values demonstrated by individuals with DM and DM+AMP [34]. Impaired ambulatory ability in both individuals with DM and those with DM+AMP may indicate health concerns. A review concerning functional tests indicates a relationship between poor 6MWT performance and mortality [35]. This finding is pertinent to the present study based on the strong correlation $(r=0.892)$ of 2MWT and 6 MWT results [21].
Similar to the 2MWT, TUG performance was slower in the DM+AMP group compared with the DM and NA groups. TUG times for the DM+AMP group were somewhat slower than those found in previous studies. Samitier et al. noted a mean performance time of $14 \mathrm{~s}$ for individuals with AMP [36], and Van de Meent et al. noted a mean performance time of $15 \mathrm{~s}$ for individuals with transfemoral amputation [37]. The greater time necessary to complete the TUG may arise from the presence of DM in this group, which was not consistently the case in previous studies. The elapsed time to complete the TUG classifies people with DM+AMP in this study as "slow," which is associated with greater risk for both morbidity and mortality. A TUG performance time of greater than $20 \mathrm{~s}$ presents up to a fourfold increase in morbidity risk, and a "slow" classification confers a 31 percent risk of 1 yr mortality [38-39]. Increased risk of falling may be partly responsible for the increased risk of morbidity and mortality. A TUG performance time of $\geq 19 \mathrm{~s}$ is predictive of falling after AMP [40]. Ambulatory ability indicates that individuals with DM and DM+AMP are at greater risk of morbidity and mortality than NAs.

PA and walking performance were correlated for both DM and DM+AMP groups. This finding is consistent with similar studies performed in other patient populations with lower-limb dysfunction. For example, patients with osteoarthritis demonstrate an association between PA and 20-m walk test performance [41]. Latent growth curve modeling suggests that PA is a key moderator of functional performance and disability in people with DM [42]. Furthermore, recent evidence suggests that lifestyle interventions incorporating increased PA can 
improve functional performance in patients with DM [43]. These findings are important because they suggest that PA confers functional performance benefits to individuals with DM and DM+AMP. This relationship to functional performance indicates the importance of PA because quality of life is related to both mobility and balance [1]. These factors are crucial in the ability to care for oneself [1]. Functional performance is also related to lifespan $[31,39]$. Ultimately, the correlations between PA and functional performance suggest that individuals with DM and DM+AMP may be able to improve their functional performance through $\mathrm{PA}$, thereby potentially improving individuals' quality of life and longevity.

Previous studies in older populations suggest that comorbidities are associated with impaired walking performance [44-46]. PA is also associated with walking performance [3-4]. We hypothesized that a relationship between PA and number of comorbidities might explain the deficit in functional performance exhibited by participants with DM+AMP and DM. No such relationship existed. It is possible that the present study is underpowered to detect a relationship between comorbidities and PA. Alternately, the effect of AMP and DM, or DM alone, may limit walking performance to a far greater degree than other comorbidities. Such an effect would overshadow any limitations provided by comorbidities.

Several limitations were present in this study. The PA performed by the NA group in this study classifies them in the "above average" category (5,270-8,099 steps/d) as defined by Tudor-Locke et al. [25]. The DM group was classified as exhibiting "below average" PA $(2,706-$ 4,760 steps/d), and the DM+AMP group was classified as exhibiting the "lowest" category of PA $(<2,706$ steps/d) [25]. While the high level of PA in the NA group could have exacerbated between-group differences, the results align with other studies comparing individuals with LLA with nondisabled controls $[8,47]$. The magnitude of differences in functional performance of NAs and people with $\mathrm{DM}$ or $\mathrm{DM}+\mathrm{AMP}$ suggests that the differences would remain intact even if the NAs were less active. Similarly, time since diabetes diagnosis was not controlled for and could enhance the generalizability of our findings. Diabetic severity was also not controlled. HbA1c measurements, however, were similar upon comparison of the DM and DM+AMP groups, suggesting that diabetic severity was similar in these groups. In terms of measures, the variability in course length and course surface of the 2MWT could be viewed as a limita- tion. We investigated the potential relationship of course length to distance walked, finding no correlation between the 2MWT course length and PA. Also, although 2MWT courses were all flat, nonslippery, well lit, and clear of obstacles, other surface characteristics and footwear were not controlled.

\section{CONCLUSIONS}

PA levels and intensity are lower in people with DM, and lower still in people with DM and LLA, when compared to NAs. This is clinically relevant because PA is directly related to quality of life, morbidity risk, and longevity. PA is also related to functional performance in people with DM and people with DM and LLA. This novel finding suggests the ability to walk may affect overall performance of PA. Alternately, PA may alleviate walking problems. This possibility is of great interest given that issues with walking may be modifiable by improved levels and intensity of PA. Finally, PA was not related to number of comorbidities, suggesting that factors beyond multiple morbidities account for group differences in PA performance. Future studies should focus on interventions to increase PA in these clinical populations with the goal of improved functional performance.

\section{ACKNOWLEDGMENTS}

\section{Author Contributions:}

Study concept and design: R. J. Paxton, C. L. Christiansen, K. A. Sherk. Acquisition of data: R. J. Paxton, A. M. Murray.

Analysis and interpretation of data: R. J. Paxton, C. L. Christiansen, J. E. Stevens-Lapsley.

Drafting of manuscript: R. J. Paxton, C. L. Christiansen. Critical revision of manuscript for important intellectual content: A. M. Murray, K. A. Sherk, J. E. Stevens-Lapsley.

Statistical analysis: R. J. Paxton.

Study supervision: R. J. Paxton, C. L. Christiansen.

Financial Disclosures: The authors have declared that no competing interests exist.

Funding/Support: This material was based on work supported by the National Institutes of Health (grant T32-AG00279, K12-HD05593).

Institutional Review: All study procedures were approved by the Colorado Multiple Institutional Review Board. All participants provided written informed consent prior to study participation.

Participant Follow-Up: The authors plan to notify participants of publication of study results.

Disclaimer: The contents do not represent the views of the Department of Veterans Affairs or the U.S. Government. 


\section{REFERENCES}

1. Davis JC, Bryan S, Li LC, Best JR, Hsu CL, Gomez C, Vertes KA, Liu-Ambrose T. Mobility and cognition are associated with wellbeing and health related quality of life among older adults: A cross-sectional analysis of the Vancouver Falls Prevention Cohort. BMC Geriatr. 2015;15(1): 75. [PMID:26142897] http://dx.doi.org/10.1186/s12877-015-0076-2

2. de Godoy JM, Braile DM, Buzatto SH, Longo O, Fontes OA. Quality of life after amputation. Psychol Health Med. 2002;7(4):397-400. http://dx.doi.org/10.1080/1354850021000015212

3. Lin SJ, Winston KD, Mitchell J, Girlinghouse J, Crochet K. Physical activity, functional capacity, and step variability during walking in people with lower-limb amputation. Gait Posture. 2014;40(1):140-4. [PMID:24731451] http://dx.doi.org/10.1016/j.gaitpost.2014.03.012

4. Parker K, Kirby RL, Adderson J, Thompson K. Ambulation of people with lower-limb amputations: Relationship between capacity and performance measures. Arch Phys Med Rehabil. 2010;91(4):543-9. [PMID:20382285] http://dx.doi.org/10.1016/j.apmr.2009.12.009

5. Dillingham TR, Pezzin LE, Shore AD. Reamputation, mortality, and health care costs among persons with dysvascular lower-limb amputations. Arch Phys Med Rehabil. 2005; 86(3):480-6. [PMID:15759232]

http://dx.doi.org/10.1016/j.apmr.2004.06.072

6. Karvonen-Gutierrez CA, Sowers MR, Heeringa SG. Sex dimorphism in the association of cardiometabolic characteristics and osteophytes-defined radiographic knee osteoarthritis among obese and non-obese adults: NHANES III. Osteoarthritis Cartilage. 2012;20(7):614-21.

[PMID:22521953]

http://dx.doi.org/10.1016/j.joca.2012.02.644

7. Morrato EH, Hill JO, Wyatt HR, Ghushchyan V, Sullivan PW. Physical activity in U.S. adults with diabetes and at risk for developing diabetes, 2003. Diabetes Care. 2007; 30(2):203-9. [PMID:17259482]

http://dx.doi.org/10.2337/dc06-1128

8. Bussmann JB, Grootscholten EA, Stam HJ. Daily physical activity and heart rate response in people with a unilateral transtibial amputation for vascular disease. Arch Phys Med Rehabil. 2004;85(2):240-4. [PMID:14966708] http://dx.doi.org/10.1016/S0003-9993(03)00485-4

9. Steeves JA, Murphy RA, Crainiceanu CM, Zipunnikov V, Van Domelen DR, Harris TB. Daily patterns of physical activity by type 2 diabetes definition: Comparing diabetes, prediabetes, and participants with normal glucose levels in NHANES 2003-2006. Prev Med Rep. 2015;2:152-7. http://dx.doi.org/10.1016/j.pmedr.2015.02.007
10. van den Berg-Emons RJ, Bussmann JB, Stam HJ. Accelerometry-based activity spectrum in persons with chronic physical conditions. Arch Phys Med Rehabil. 2010;91(12): 1856-61. [PMID:21112426] http://dx.doi.org/10.1016/j.apmr.2010.08.018

11. Herbst A, Kapellen T, Schober E, Graf C, Meissner T, Holl RW; DPV-Science-Initiative. Impact of regular physical activity on blood glucose control and cardiovascular risk factors in adolescents with type 2 diabetes mellitus-A multicenter study of 578 patients from 225 centres. Pediatr Diabetes. 2015;16(3):204-10. [PMID:24888254] http://dx.doi.org/10.1111/pedi.12144

12. Deans SA, McFadyen AK, Rowe PJ. Physical activity and quality of life: A study of a lower-limb amputee population. Prosthet Orthot Int. 2008;32(2):186-200. [PMID:18569887] http://dx.doi.org/10.1080/03093640802016514

13. Halsne EG, Waddingham MG, Hafner BJ. Long-term activity in and among persons with transfemoral amputation. J Rehabil Res Dev. 2013;50(4):515-30. [PMID:23934872] http://dx.doi.org/10.1682/JRRD.2012.04.0066

14. John D, Tyo B, Bassett DR. Comparison of four ActiGraph accelerometers during walking and running. Med Sci Sports Exerc. 2010;42(2):368-74. [PMID:19927022] http://dx.doi.org/10.1249/MSS.0b013e3181b3af49

15. Kozey SL, Staudenmayer JW, Troiano RP, Freedson PS. Comparison of the ActiGraph 7164 and the ActiGraph GT1M during self-paced locomotion. Med Sci Sports Exerc. 2010;42(5):971-6. [PMID:19997000] http://dx.doi.org/10.1249/MSS.0b013e3181c29e90

16. Freedson PS, Melanson E, Sirard J. Calibration of the Computer Science and Applications, Inc. accelerometer. Med Sci Sports Exerc. 1998;30(5):777-81. [PMID:9588623] http://dx.doi.org/10.1097/00005768-199805000-00021

17. Boonstra AM, Fidler V, Eisma WH. Walking speed of normal subjects and amputees: Aspects of validity of gait analysis. Prosthet Orthot Int. 1993;17(2):78-82. [PMID:8233772]

18. Brooks D, Hunter JP, Parsons J, Livsey E, Quirt J, Devlin M. Reliability of the two-minute walk test in individuals with transtibial amputation. Arch Phys Med Rehabil. 2002;83(11):1562-5. [PMID:12422326] http://dx.doi.org/10.1053/apmr.2002.34600

19. Brooks D, Parsons J, Hunter JP, Devlin M, Walker J. The 2minute walk test as a measure of functional improvement in persons with lower limb amputation. Arch Phys Med Rehabil. 2001;82(10):1478-83. [PMID:11588757] http://dx.doi.org/10.1053/apmr.2001.25153

20. Schoppen T, Boonstra A, Groothoff JW, de Vries J, Göeken LN, Eisma WH. The timed "up and go" test: Reliability and validity in persons with unilateral lower limb amputation. Arch Phys Med Rehabil. 1999;80(7):825-8. 


\section{[PMID: 10414769]}

http://dx.doi.org/10.1016/S0003-9993(99)90234-4

21. Butland RJ, Pang J, Gross ER, Woodcock AA, Geddes DM. Two-, six-, and 12-minute walking tests in respiratory disease. BMJ. 1982;284(6329):1607-8. [PMID:6805625] http://dx.doi.org/10.1136/bmj.284.6329.1607

22. Podsiadlo D, Richardson S. The timed "Up \& Go": A test of basic functional mobility for frail elderly persons. J Am Geriatr Soc. 1991;39(2):142-48. [PMID:1991946]

http://dx.doi.org/10.1111/j.1532-5415.1991.tb01616.x

23. Kapetanovic MC, Lindqvist E, Nilsson JA, Geborek P, Saxne T, Eberhardt K. Development of functional impairment and disability in rheumatoid arthritis patients followed for 20 years: Relation to disease activity, joint damage, and comorbidity. Arthritis Care Res (Hoboken). 2015;67(3):340-8. [PMID:25186552] http://dx.doi.org/10.1002/acr.22458

24. Harris TJ, Owen CG, Victor CR, Adams R, Cook DG. What factors are associated with physical activity in older people, assessed objectively by accelerometry? Br J Sports Med. 2009;43(6):442-50. [PMID:18487253] http://dx.doi.org/10.1136/bjsm.2008.048033

25. Tudor-Locke C, Schuna JM Jr, Barreira TV, Mire EF, Broyles ST, Katzmarzyk PT, Johnson WD. Normative steps/day values for older adults: NHANES 2005-2006. J Gerontol A Biol Sci Med Sci. 2013;68(11):1426-32. [PMID:23913932] http://dx.doi.org/10.1093/gerona/glt116

26. Booth FW, Roberts CK, Laye MJ. Lack of exercise is a major cause of chronic diseases. Compr Physiol. 2012;2(2):1143-211. [PMID:23798298]

27. Dormandy J, Heeck L, Vig S. Predictors of early disease in the lower limbs. Semin Vasc Surg. 1999;12(2):109-17. [PMID:10777237]

28. Jude EB, Oyibo SO, Chalmers N, Boulton AJ. Peripheral arterial disease in diabetic and nondiabetic patients: A comparison of severity and outcome. Diabetes Care. 2001; 24(8):1433-7. [PMID:11473082] http://dx.doi.org/10.2337/diacare.24.8.1433

29. Global recommendations on physical activity for health. [Internet]. Geneva (Switzerland): World Health Organization; 2006 [cited 2017, Jan 3]. Available from: http://apps.who.int/ iris/bitstream/10665/44399/1/9789241599979 eng.pdf

30. Kristensen MT, Holm G, Kirketerp-Møller K, Krasheninnikoff $\mathrm{M}$, Gebuhr P. Very low survival rates after non-traumatic lower limb amputation in a consecutive series: What to do? Interact Cardiovasc Thorac Surg. 2012;14(5):543-7. [PMID:22298857] http://dx.doi.org/10.1093/icvts/ivr075

31. Lee IM, Skerrett PJ. Physical activity and all-cause mortality: What is the dose-response relation? Med Sci Sports
Exerc. 2001;33(6 Suppl):S459-S471; discussion S493S454. [PMID:11427772]

32. Lee CD, Folsom AR, Blair SN. Physical activity and stroke risk: A meta-analysis. Stroke. 2003;34(10):2475-81.

[PMID:14500932]

http://dx.doi.org/10.1161/01.STR.0000091843.02517.9D

33. Gremeaux V, Damak S, Troisgros O, Feki A, Laroche D, Perennou D, Benaim C, Casillas JM. Selecting a test for the clinical assessment of balance and walking capacity at the definitive fitting state after unilateral amputation: A comparative study. Prosthet Orthot Int. 2012;36(4):415-22.

[PMID:22389424]

http://dx.doi.org/10.1177/0309364612437904

34. Connelly DM, Thomas BK, Cliffe SJ, Perry WM, Smith RE. Clinical utility of the 2-minute walk test for older adults living in long-term care. Physiother Can. 2009; 61(2): 78-87. [PMID:20190990] http://dx.doi.org/10.3138/physio.61.2.78

35. Solway S, Brooks D, Lacasse Y, Thomas S. A qualitative systematic overview of the measurement properties of functional walk tests used in the cardiorespiratory domain. Chest. 2001;119(1):256-70. [PMID:11157613]

http://dx.doi.org/10.1378/chest.119.1.256

36. Samitier CB, Guirao L, Costea M, Camós JM, Pleguezuelos E. The benefits of using a vacuum-assisted socket system to improve balance and gait in elderly transtibial amputees. Prosthet Orthot Int. 2016;40(1):83-8.

[PMID:25261489]

http://dx.doi.org/10.1177/0309364614546927

37. Van de Meent H, Hopman MT, Frölke JP. Walking ability and quality of life in subjects with transfemoral amputation: A comparison of osseointegration with socket prostheses. Arch Phys Med Rehabil. 2013;94(11):2174-8.

[PMID:23774380] http://dx.doi.org/10.1016/j.apmr.2013.05.020

38. Huisman MG, van Leeuwen BL, Ugolini G, Montroni I, Spiliotis J, Stabilini C, de'Liguori Carino N, Farinella E, de Bock GH, Audisio RA. "Timed Up \& Go": A screening tool for predicting 30-day morbidity in onco-geriatric surgical patients? A multicenter cohort study. PLoS ONE. 2014;9(1):e86863. Erratum in: PLoS One. 2014;9(7): e103907. [PMID:24475186]

http://dx.doi.org/10.1371/journal.pone.0086863

39. Robinson TN, Wu DS, Sauaia A, Dunn CL, StevensLapsley JE, Moss M, Stiegmann GV, Gajdos C, Cleveland JC Jr, Inouye SK. Slower walking speed forecasts increased postoperative morbidity and 1-year mortality across surgical specialties. Ann Surg. 2013;258(4):582-8; discussion 588-90. [PMID:23979272]

40. Dite W, Connor HJ, Curtis HC. Clinical identification of multiple fall risk early after unilateral transtibial amputation. Arch Phys Med Rehabil. 2007;88(1):109-14. 
JRRD, Volume 53, Number 6, 2016

\section{[PMID:17207685]}

http://dx.doi.org/10.1016/j.apmr.2006.10.015

41. Dunlop DD, Song J, Semanik PA, Sharma L, Chang RW. Physical activity levels and functional performance in the osteoarthritis initiative: A graded relationship. Arthritis Rheum. 2011;63(1):127-36. [PMID:20862681]

http://dx.doi.org/10.1002/art.27760

42. Palmer RF, Espino DV, Dergance JM, Becho J, Markides $\mathrm{K}$. The role of physical activity and diabetes status as a moderator: Functional disability among older Mexican Americans. Age Ageing. 2012;41(6):752-8.

[PMID:23052844] http://dx.doi.org/10.1093/ageing/afs106

43. Rejeski WJ, Bray GA, Chen SH, Clark JM, Evans M, Hill JO, Jakicic JM, Johnson KC, Neiberg R, Ip EH, Look AHEAD Research Group. Aging and physical function in type 2 diabetes: 8 years of an intensive lifestyle intervention. J Gerontol A Biol Sci Med Sci. 2015;70(3):345-53. [PMID:24986062] http://dx.doi.org/10.1093/gerona/glu083

44. Cesari M, Onder G, Russo A, Zamboni V, Barillaro C, Ferrucci L, Pahor M, Bernabei R, Landi F. Comorbidity and physical function: Results from the aging and longevity study in the Sirente geographic area (ilSIRENTE study). Gerontology. 2006;52(1):24-32. [PMID:16439821] http://dx.doi.org/10.1159/000089822

45. McDermott MM, Guralnik JM, Ferrucci L, Criqui MH, Greenland P, Tian L, Liu K, Tan J. Functional decline in lower-extremity peripheral arterial disease: Associations with comorbidity, gender, and race. J Vasc Surg. 2005; 42(6):1131-7. [PMID:16376203] http://dx.doi.org/10.1016/j.jvs.2005.08.010
46. Volpato S, Blaum C, Resnick H, Ferrucci L, Fried LP, Guralnik JM; Women's Health and Aging Study. Comorbidities and impairments explaining the association between diabetes and lower extremity disability: The Women's Health and Aging Study. Diabetes Care. 2002; 25(4):678-83. [PMID:11919124] http://dx.doi.org/10.2337/diacare.25.4.678

47. Bussmann JB, Schrauwen HJ, Stam HJ. Daily physical activity and heart rate response in people with a unilateral traumatic transtibial amputation. Arch Phys Med Rehabil. 2008;89(3):430-4. [PMID:18295619] http://dx.doi.org/10.1016/j.apmr.2007.11.012

Submitted for publication August 25, 2015. Accepted in revised form December 1, 2015.

This article and any supplementary material should be cited as follows:

Paxton RJ, Murray AM, Stevens-Lapsley JE, Sherk KA, Christiansen CL. Physical activity, ambulation, and comorbidities in people with diabetes and lower-limb amputation. J Rehabil Res Dev. 2016;53(6):1069-78. http://dx.doi.org/10.1682/JRRD.2015.08.0161

ORCID: Cory L. Christiansen, PT, PhD: 0000-00015549-5010

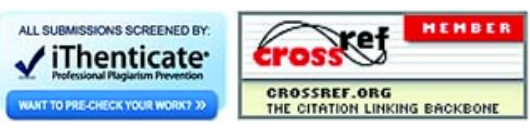

